\title{
Sexually Transmitted Infections, Sexuality and STI Stigma among Nepalese youth and adults
}

\author{
Pokhrel D.B \\ Professor \& Head, \\ Department of Dermatology \& Venereology \\ Institute of Medicine, Maharajgunj Campus, \\ TU Teaching Hospital, \\ Kathmandu, Nepal.
}

\section{Abstract}

A 5 year long prospective study on patients with Sexual problems among 1852 male adolescents, youths and adults of ages $15-50$ years presenting with the sexual problems including that of sexually transmitted illnesses, was conducted to find out the prevalence of self STI stigma in relation to their sexual behavior and STIs. The study revealed that only $27.6 \%$ had one or more STIs during the time of their evaluation but a significant number $(72.4 \%)$ of sexually active male youths and adults were being self stigmatized of having STIs, although they were not having any STI during the study time. Almost $86 \%$ of the study populations were having extramarital sexual relationships. Although almost $40 \%$ of them were found to be using condoms at some point of time, only $8 \%$ were found to have used it consistently. Majority of them were having heterosexual contact with vaginal intercourse but a significant number of them were also having oral and anal sex.

Key words: Sexually Transmitted Illness, sexuality and STI Stigma

\section{Introduction}

Globally Sexually Transmitted infections are among the most common public health problems with their prevalence ranging widely (From less than $1 \%$ to up to $40 \%$ among the reproductive age group population of different communities. It is estimated that every year more than 340 million new cases of curable STIs occur globally ${ }^{1,2}$ and it is also estimated that 1 in 4 Americans have STIs ${ }^{3}$ at any point of time.

STIs in Nepal have also been considered as a major group of diseases causing significant morbidity among some targeted group of population including the youths. It is been dealt along with HIV by a separate wing of the Department of health from the ministry of health and population of Government of Nepal, called NCASC (National center for AIDS and STD control) in close coordination with many other national and international non governmental organizations. The true prevalence of STI in Nepal is not known but small scale studies carried out in different groups of population have reported STIs to be one of the major public health problem ${ }^{4}$ of the country.

The sufferings from STIs are reported from the ancient time with different descriptions, which shows that the illnesses are as old as the humankind. However, STIs had not been able to grasp the significant importance among public health, till its relationship with HIV infection has been strongly established..$^{5^{\prime} 6^{7} 7}$ Today, STIs stand together with HIV infection as the major public health issue and billions of dollars are being spent globally to find the ways on how to provide efficient treatment and how to avoid STIs. The success of such efficient STI management program in the long run, is expected to significantly reduce HIV transmission as evidenced by the reports of Rakai, Masaka and Mwanza study from 1991-1998. ${ }^{7}$ Most of the STI management programs give major focus to diagnose treat and prevent STIs, but almost negligible attention is given to cover up the psychological aspects of the disease. Stigma, which is defined as "the negative judgment and prejudice towards those who are infected and affected', is very high among STI population. STIs being considered as a social taboo in the society, persons infected to it are not socio-culturally accepted. Still a high degree of discriminations (defined as 'unequal treatment to those who are known as infected or affected') prevail to those who have any STIs, even by the health care providers. The fear of discrimination further increases the tendency to hide the disease and thus promotes the disease progression and thereby causing unlimited burden of self-stigmatization on STIs.

As a consequence of a high level of stigma and fear of discrimination on STIs within the society, in one hand it leads to the tendency to hide the infection at the individual level, which further helps to increase the morbidity caused by the disease progression and their sequele as well as 
promoting its transmission to others. And in other hand, it further causes significant anxiety or depression to the affected individual even when the individual is completely cured of the infection or there is no such infection at all, ultimately increasing the sufferings of the individual and his/her family to a greater extent.

\section{Objectives of the study}

1 . To identify the prevalence of self stigma among youths and adults.

2. To find out the true prevalence of STIs among those youths and adults having STI related symptoms.

3. To study the pattern of sexual behavior and sexuality among them.

4. To find out the common mode of sexual act among them.

\section{Methodology \\ Type of study: \\ Duration:}

2007)

Prospective study

5 year (July 2002- June

Study: "Sexuality, Sexually Transmitted Infections and STI Stigma among Nepalese Youths and adults"

Place: Department of DermatoVenereology of TUTH and private clinic

\section{Method of information collection:}

Defined Format of proforma on:

Demographic data, sexual history, symptoms, clinical findings, laboratory findings and diagnosis along with the individual's self evaluation status on STIs

\section{Results}

Out of 1852 male adolescents, youths and adults with genital complaints only $28 \%$ had true STIs and the rest $72 \%$ were either already cured or had no STIs at all, but were having strong self stigma of STIs. The majority of the study population belonged to youth and young adults and slightly more than half were married (Table 1).

\section{Table 1.}

Age wise distribution and Marital status of the study Population

$\begin{array}{llll}\text { Age } & \text { Married } & \text { Unmarried } & \text { Total } \\ 15-25 & 163 & 655 & 818 \\ 26-35 & 710 & 212 & 922 \\ 36-45 & 86 & 26 & 112 \\ & & & \mathbf{1 8 5 2}\end{array}$

Out of the total study population, only $27.6 \%$ of them were found to have one or more STIs during the time of the study and the rest (72.4\%) although strongly believed that they have one form or other of STIs, were not having any STIs in reference to the clinical and available laboratory tests (Table 2, Fig.1).

Table 2. Diagnosed STIs $(n=511)$ among the total patients with genital symptoms $(n=1852)$

\begin{tabular}{|r|l|l|l|}
\hline S.No & Diagnosed STI & Number of Patients & Percentage \\
\hline 1. & Non Gonococcal Urethritis* & 218 & $\mathbf{1 1 . 8}$ \\
\hline 2. & Gonococcal Uretluritis & 57 & $\mathbf{3 . 0}$ \\
\hline 3. & Herpes Genitalis** & 54 & $\mathbf{2 . 9}$ \\
\hline 4. & Genital Warts** & 78 & $\mathbf{4 . 2}$ \\
\hline 5. & Syphilis & 109 & $\mathbf{5 . 9}$ \\
\hline 6. & Others: *** & 48 & $\mathbf{2 . 6}$ \\
\hline 7. & Total number of STI patients & $\mathbf{5 1 1 * * * *}$ & $\mathbf{2 7 . 6}$ \\
\end{tabular}

* Diagnosed on the basis of finding on Gram Stain on urethral swab (No GNID but $=5 \mathrm{PMNL} / \mathrm{HPF}$ ) ** Diagnosed on the basis of clinical findings *** 34 had Pearly Penile Papule, 7 Seb. keratosis, 5 Para urethral Cysts, 2 Bowens disease and 1 SCC $* * * * 44$ patients had more than one STI ( 35 had two STIs and 9 had 3 STIs) and 14 were also PLHA

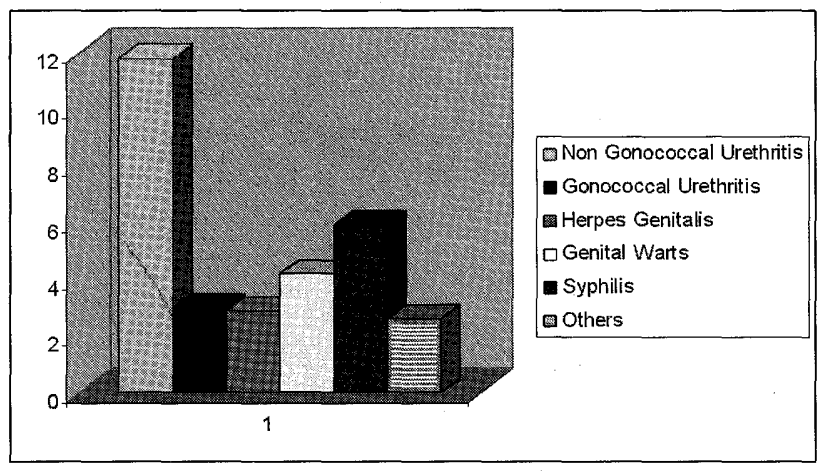

Fig.1. Percentage distribution of various STIs.

The major presenting symptoms of the study population were found to be as follows (Table 3). Burning or prickling pain, itching, sore or superficial erosion, discharge, premature ejaculation and decreased sexual desire or erectile dysfunctions etc. were among the commonest.

Table 3. Presenting symptoms related to genital problem

\begin{tabular}{|r|l|r|r|}
\hline S.no & Presenting Symptoms & No. of Pateints & Percentage \\
\hline 1. & Burning or prickling pain on the penis/urethra & 667 & 36.01 \\
\hline 2. & Itching erosion in \& around genitalia & 508 & 27.42 \\
\hline 3. & Pain during micturition & 298 & 16.09 \\
\hline 4. & Discharge per urethra/genitalia & 447 & 24.13 \\
\hline 5. & Rashes, tear or ulcer on the genitalia & 236 & 12.7 \\
\hline 6. & Fleshy growth in \& around genitalia & 177 & 9.6 \\
\hline 7 & Premature Ejaculation & 433 & 23.4 \\
\hline 8. & Decreased sexual desire & 491 & 26.5 \\
\hline 9 & Erectile dysfunction & 312 & 15.8 \\
\hline 10 & Decreased size/distorted genitalia & 156 & 8.4 \\
\hline 1 & $\begin{array}{l}\text { Others (Pigmentory changes, Scrotal swelling, } \\
\text { dysparunia etc) }\end{array}$ & 125 & 6.8 \\
\hline
\end{tabular}

Note: Nearly eighty percent $(78.3 \%, \mathrm{n}=1450)$ had more than one presenting symptoms)

Almost 2/3rd of the study population (63.5\%) gave 
history of having only vaginal sex, about $14 \%$ were having vaginal, anal and oral sex and almost $18 \%$ were having vaginal and oral sex. A small number $(<5 \%)$ however did not have any heterosexual contact.

(Table 4, Fig.2).

\section{Table 4. Mode of sexual act:}

\begin{tabular}{|c|l|r|r|}
\hline S. No & Mode of sexual act & $\begin{array}{r}\text { Number of } \\
\text { Persons }\end{array}$ & Percentage \\
\hline 1 & Vaginal & 1176 & 63.5 \\
\hline 2. & Vaginal + Anal toral & 257 & 13.9 \\
\hline 3. & Vaginal + Oral & 332 & 17.9 \\
\hline 4. & MSM & 23 & 1.2 \\
\hline 5. & Others* & 27 & 1.5 \\
\hline 6. & No Sexual relation** & 37 & 2.0 \\
\hline 7. & Total & 1852 & 100 \\
\hline
\end{tabular}

* Others include: Mutual masturbation, rubbing/pressing the genitalia against the different parts of body surface etc

* * Self masturbation, use of sex toys
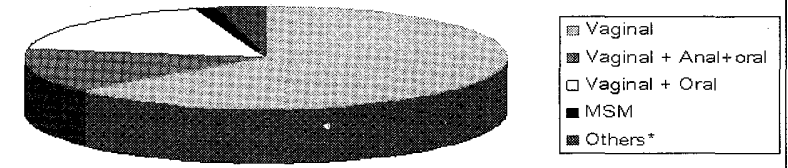

\section{Fig.2. Percentage distribution of modes of sexual contact of patients.}

$58 \%$ of the study population had more than one partner. $27.8 \%$ had single extramarital sexual partner and almost two percent had no sexual contact

Table 5. Sexual Partners

Number of sexual Partners More than one partner 1076

Single partner other than spouse

Relation only with spouse 224

Never had any contact 37

Total

\section{5}

224

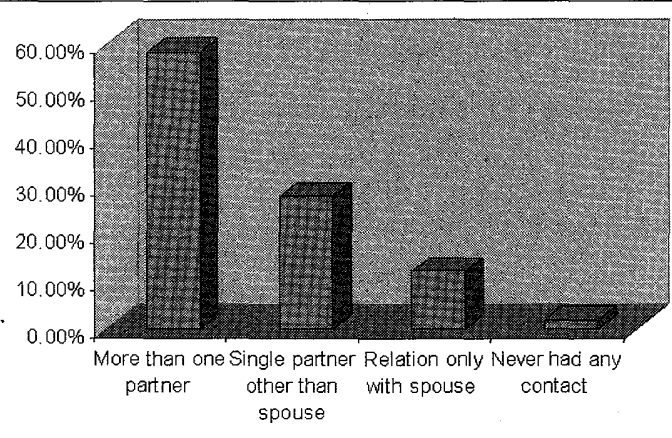

Fig.3. Sexual contact history of patients. Note: Out of the total 1591 who gave history of extramarital contact, 107 (5.8\%) gave history of single sexual contact.

Although, $49.2 \%$ of those having extramarital sex were found to have used condoms, only $7.8 \%$ were using it consistently with all of their sexual partners. 55 out of $782(7 \%)$ of those using condom replied that the condom was broken in one or more occasions.

Table 6. Condom Use within extramarital sexual contact $(\mathrm{n}=1591)$

\begin{tabular}{|c|c|c|}
\hline exual Partners & $\begin{array}{l}\text { Casual } \\
\text { Condom use } \\
456 \quad(42.4 \%)\end{array}$ & $\begin{array}{l}\text { Consistent } \\
\text { Condom Use } \\
102(9.5 \%)\end{array}$ \\
\hline her than wi & $202 \quad(39.2 \%)$ & $22(10.9 \%)$ \\
\hline ta & $658 \quad(41.4 \%)$ & $124(7.8 \%)$ \\
\hline
\end{tabular}

\section{Discussion}

Although, STI is one of the common causes of morbidity, fear of having STI with or without any risky behavior is becoming far more common among the youths of Nepal. This study has revealed that almost two thirds of the persons who presume to have STIs are not found to have any STIs even in repeated laboratory screening. Moreover, they are found to be suffering from some kind of depression or anxiety disorders reflected in the different forms of their abnormal symptoms and sexuality. Similar study carried out among 500 such population ${ }^{8}$ in 2004 has also revealed similar data. A small study done by Frank E et. $\mathrm{al}^{9}$, among the normal couple on their sexual function had revealed that $40 \%$ of men and $63 \%$ of women had some form of sexual impairment. Similarly, several studies have proved that, illiteracy with lack of sex education leads to the sexual dissatisfaction because many of them can not differentiate between what is normal and what is abnormal sex behavior. Since even those persons who confess that, they had never had any sexual contact with other partners, think that they are suffering from some STIs which have resulted in different manifestations. ${ }^{8}$ In this context, the present study clearly indicates the role of adequate sex education among the youths and the need of proper STI Counseling and psychotherapy to the sufferers.

\section{Conclusion}

The study, one of the first of this kind in Nepal, revealed that a significant number $(>72 \%)$ of male youths and adults suffering from some form of genital symptoms were on self stigma of having STIs, although they had none. Although almost $86 \%$ were having extramarital sexual relationships, only about $49 \%$ were found to be using condoms at some point of time and more over, only $8 \%$ were found to have used it consistently. More than $95 \%$ of them were having heterosexual contact. $63.5 \%$ were found to have only vaginal intercourse; 
however the rest $36.5 \%$ were also having oral and anal sex.

The study also reveals that, the lack of knowledge regarding sexual drive, sexuality and reproductive health among the youths and adults make this group vulnerable to different mode of sexual activities. Because of their indulgence in those activities, which normally is not accepted by their society and their culture, leads them to selfstigmatize on STIs and manifest with bizarre symptoms. Moreover, these groups of youths are mostly found to have anxiety or depression due to deeply rooted stigma on STIs and so are need of proper education and awareness on STI and sexuality along with counseling on STI management and psychotherapeutic support.

\section{References:}

1. World health Organization. Global Prevalence and incidence of selected curable Sexually Transmitted Infections: Overview and estimates. WHO Geneva, 2001

2. The tools of STDs population reports, issues in world health Series 1993, No. 9, Page 3-5

3. Women and teens STD crises, 2004.

4. Reports of MOH/NCASC/FHI Nepal, 2005

5. World Health Organization. WHO working group on global HIV/AIDS/STI

Surveillance. Guidelines for sexually transmitted infections surveillance. WHO/UNAIDS, Geneva, 1999

6. European STD guidelines, International Union against STI and the European office of the WHO, vol.12, Sup 3, 2001

7. Tutorials on Sexually Transmitted Infections, Topics in International Health, STI and HIV, Trustee of the Welcome trust, 2003

8. Pokhrel, D.B. "Self Stigma and Psycho Sexual Disorders a common problem of Nepalese youths of Nepal" Souvenier of the first International Conference of Dermatology in Nepal, ICD-2004.

9. Frank E, et al. Frequency of sexual Dysfunction in normal couples. N Engl J Med 1978; 299: $111-115$ 